\begin{abstract}
Iranica
Abstracta Iranica Revue bibliographique pour le domaine irano-aryen

Volume 22 | 2001

Comptes rendus des publications de 1999

\section{« Rythmes ovoïdes et quadrature du cycle ». Cahiers des musiques traditionnelles, 1997, pp.17-36.}

\title{
Rédaction
}

\section{(2) OpenEdition}

1 Journals

\section{Édition électronique}

URL : http://journals.openedition.org/abstractairanica/37367

DOI : 10.4000/abstractairanica.37367

ISSN : 1961-960X

Éditeur :

CNRS (UMR 7528 Mondes iraniens et indiens), Éditions de l'IFRI

\section{Édition imprimée}

Date de publication : 15 mai 2001

ISSN : 0240-8910

Référence électronique

Rédaction, « "Rythmes ovoïdes et quadrature du cycle ». Cahiers des musiques traditionnelles, 1997, pp. 17-36. », Abstracta Iranica [En ligne], Volume 22 | 2001, document 655, mis en ligne le 17 février 2010, consulté le 13 octobre 2020. URL : http://journals.openedition.org/abstractairanica/37367 ; DOI : https://doi.org/10.4000/abstractairanica.37367

Ce document a été généré automatiquement le 13 octobre 2020

Tous droits réservés 


\section{« Rythmes ovoïdes et quadrature du cycle ». Cahiers des musiques traditionnelles, 1997, pp. 17-36.}

\section{Rédaction}

Cet article analyse les subtilités rythmiques qui font la spécificité de certaines musiques d'Asie intérieure et qui, bien qu'étant d'une extrême importance pour les interprètes, ne sont jamais prises en compte par les théoriciens. Les exemples sont tirés des traditions professionnelles baloutche et tadjik-ouzbek, mais on peut en trouver de semblables dans de nombreuses cultures. Les analyses réalisées avec des moyens techniques très fins, remettent profondément en question les notions de pulsation et de temps fort sur lesquelles se sont appuyées la plupart des théories du rythme, tant en Orient qu'en Occident.

\section{INDEX}

Thèmes : 17.1.Musique

\section{AUTEURS}

\section{RÉDACTION}

Directeur de la revue et secrétariats (Paris et Téhéran) 